\title{
SILICA EXTRACTION FROM RICE HUSK AS A SLOW RELEASE FERTILIZER USING MICROWAVE ASSISTED EXTRACTION
}

\author{
Indriani Dina Wahyu ${ }^{1 *}$, Barunawati Nunun ${ }^{2}$, Sumarlan Sumardi Hadi ${ }^{1}$, Teresia Laura ${ }^{1}$ \\ ${ }^{1}$ Department of Agricultural Engineering, Faculty of Agricultural Technology, \\ University of Brawijaya, Malang, Indonesia \\ ${ }^{2}$ Department of Agricultural Cultivation, Faculty of Agriculte, University of Brawijaya, \\ Malang, Indonesia \\ *E-mail: dinawahyu@ub.ac.id
}

\begin{abstract}
The utilization of waste as raw materials is one of the alternatives in applying the "zero waste" principal. Rice husk is one of the wastes of rice plantation which has very high silica content at around $80-90 \%$. The extraction of silica from rice husk can be used to make slow release fertilizer. Slow release fertilizer is a fertilizer with a nutrient release mechanism that periodically follows the pattern of nutrient absorption by plants. This study aims to optimize rice husk tablets formulation by extraction using Microwave Assisted Extraction (MAE) and to determine the physical and chemical properties of the results of rice husk extract tablets. This study used a Completely Randomized Design (CRD) with two factors, namely the concentration of $\mathrm{KOH}$ with variations in solvents $2.5 \%, 5 \%$, and $7.5 \%$ and warm-up durations of $5,7.5$ and 10 minutes. The largest hardness value was $3,356 \mathrm{kgf}$ in $7.5 \% \mathrm{KOH}$ with 10 minutes in microwave. The largest yield of silica was $7.5 \% \mathrm{KOH}$ with the longest heating time of 10 minutes of $5.30 \%$. Through XRF analysis, it was found that the largest silica value was $6.51 \%$ at $5 \% \mathrm{KOH}$ with a heating time of 5 minutes. Based on the comparison with the conventional heating method, the results of extraction did not reach optimum results of silica extract $(21.8 \%)$, whereas in this research the yield obtained was $6.51 \%$. Thus, based on these results, heating using microwave did not produce optimal silica results.
\end{abstract}

\section{KEY WORDS}

Extraction, rice husk silica, slow release fertilizer.

Rice husk, or often called husks, is one of the layers wrapping rice seeds that will be separated and become rarely used thus generates waste. The main content of rice husk is silica. Silica rice husk has a high-water resistance to chemical compounds of fertilizer. Silica has a role to increase productivity and strengthen plant growth; therefore it is resistant to pest attacks. The silica contained in soil is depleted every year because there is no return of silica (Si) into the soil. The potential for silica loss from tropical soil reaches $54.2 \mathrm{~kg}$ per ha every year. These problems can be overcome by making a slow release fertilizer. The application of the silica pellet method is closely related to the method of slow adsorption of nutrients on the soil. Not all fertilizers given to plants can be absorbed; some will be carried away by groundwater or degraded, so the fertilization is inefficient. The tablet fertilizer application allows plants to absorb nutrients throughout the period of growth by minimizing the risk of nutrient loss due to leaching during irrigation and avoiding the risk of excesses dissolved salt.

\section{MATERIALS AND METHODS OF RESEARCH}

The research was conducted in January 2018 until April 2018 at the Laboratory of Food and Agricultural Processing Technology in the Faculty of Agricultural Technology, University of Brawijaya, Central Laboratory of Life Sciences (LSIH), Advanced FMIPA Mineral and Materials Laboratory, State University of Malang, Biology Laboratory, University of Muhammadiyah Malang and Laboratory Chemical Engineering of Malang State Polytechnic. 
The materials used in the study were rice husk, hydrochloric acid (HCL) $1 \mathrm{M}$, potassium hydroxide $(\mathrm{KOH}) 1 \mathrm{M}$ and distilled water.

The experimental design used in this experiment was factorial Completely Randomized Design. The first factor is the $\mathrm{KOH}$ concentration consisting of 3 levels namely $2.5 \%, 5 \%$ and $7.5 \%$ and the second factor is the comparison of duration consisting of 3 levels namely 5 minutes, 7.5 minutes and 10 minutes. This study consisted of 9 combined treatments, where each treatment was repeated 3 times, therefore 27 units were experimented.

Firstly, the rice husk was washed. Clean rice husk was dried in an oven at a temperature of $60^{\circ} \mathrm{C}$ for 24 hours. Dry rice husks were then grind using a blender, to obtain a uniform size, then sieved with a mesh size of 35 or a $0.5 \mathrm{~mm}$ sieve hole.

Rice husk was weighed as much as 10 grams and put into a $250 \mathrm{ml}$ beaker glass. Then60 $\mathrm{ml}$ of potassium hydroxide $(\mathrm{KOH})$ was added into the beaker glass. The concentration of $\mathrm{KOH}$ used is $2.5 \%, 5 \%$ and $7.5 \%$. Mixture of rice husk with $\mathrm{KOH}$ was left for 1 hour. The next step was heating using a Microwave with 100 watts of power for 5 minutes, 7.5 minutes and 10 minutes. The sample was left for 24 hours; the rice husk was then filtered using a filter cloth to separate the sediment from the filtrate. The remaining filtrate was $\mathrm{pH}$ adjusted using $\mathrm{HCl}$ to get a $\mathrm{pH}$ of 7 . The filtrate which reached $\mathrm{pH} 7$ formed a fine powder. The fine powder formed was dried in an oven with a temperature of $110^{\circ} \mathrm{C}$ for 3 hours. The extracted silica was then formed into tablet using tabletting machine.

The formation of rice husk powder to tablets was done using tabletting machine. The average weight of extracted powder was $0.5 \mathrm{~g}$ per tablet. Then extracted powder was put into a tablet forming device, then pressed with a hammer, which hardened and solidified the powder.

The observation parameters for the yield of extraction were carried out using XRF and the hardness was determined using a penetrometer. The method used in this study was the experimental research method by conducting experiments to see the effect of $\mathrm{KOH}$ and the duration of extraction using microwave. Data analysis was performed using Analysis of Variance (ANOVA).

The cone attached to the tip of the penetrometer will be vertically straight up on the material that will be tested, then pressed into the material with a fixed compressive force. At a certain depth, the magnitude of the vertical pressure is shown to press the tool/the material and divided into a lower plate. The principle is similar to a tensile test but the method for this test is by pressing the material until the material is cracked. The results on the parameters will be obtained at the end of the process.

The recovery is a comparison between the mass of the product produced to the mass of the raw material used. Procedure for analysis of yield is: (Novari et al, 2007):

a) Weight of dry husk ingredients (grams);

b) Weight of fertilizer produced (gram).

$$
\text { Yield }(\%)=[(\text { Final Mass }) /(\text { Initial Mass })] \times 100 \%
$$

The sample of rice husk powder was placed on a holder $( \pm 10 \mathrm{~mm})$. Nonconductive samples need to be coated by Au-Pd, so that the sample is more conductive. The sample was then put into a SEM chamber then pumped (High Vacuum or Low Vacuum) and waited until vacuum. Samples are in the form of powder and solids. The synthesis results are then inserted into the tube and measured using X-rays.

The solubility of tablets is calculated based on the duration of the tablet dissolves into fine particles both in the soil and in water. The solubility value in water is calculated using a stopwatch. The solubility value in the soil is carried out by observing the soil that has been applied by rice husk tablets.

\section{RESULTS AND DISCUSSION}

The results of the hardness test of rice husk tablets obtained in the study ranged from 1,131-3,356 kgf. The average value of hardness obtained can be seen in Figure 1 . 


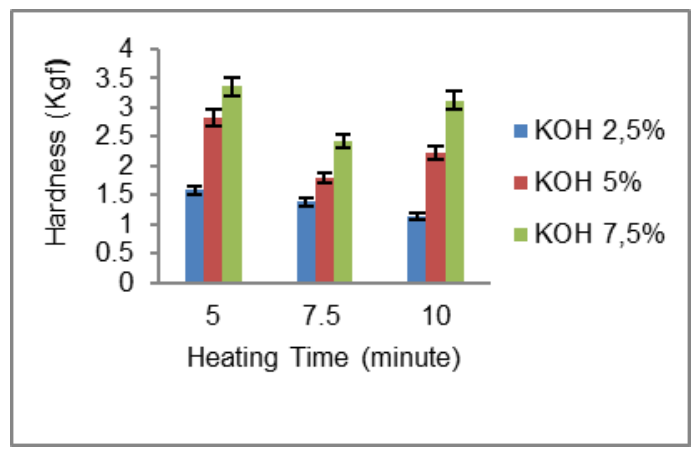

Figure 1 - Relationship between Heating Duration (minute) and Hardness Test Value (kgf)

Based on Figure 1 the trend tends to increase in each treatment. The highest hardness value of rice husk tablets increased to $3.356 \mathrm{kgf}$, at the treatment of $7.5 \% \mathrm{KOH}$ concentration with a warm up duration of 5 minutes, while the lowest value of hardness of rice husk tablets was $1.131 \mathrm{kgf}$, at the treatment of $2.5 \% \mathrm{KOH}$ concentration with a heating duration of 10 minutes. Based on the analysis of variance, it is showed that the $\mathrm{KOH}$ concentration factor and the heating time had a significant effect $(P>0.05)$ on the value of hardness. Hardness is the nature of a solid object in terms of its resistance to rupture due to the presence of compressive forces that are not deformed [8]. The smaller the compressive value, the greater the hardness, while the greater the compressive value, the lower the material hardness. It is because the material should be weak (Sumarmono, 2012).

The results of the extraction of silica extract from rice husk obtained in the study ranged from 1.48 to $5.30 \%$. The average yield obtained can be seen in Figure 2 .

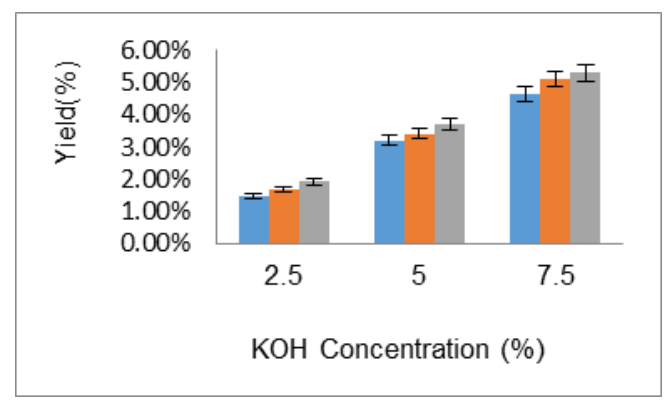

Figure 2 - Rice Husk Silica Extraction Yield

Based on Figure 2 the graph tends to increase in each treatment. The highest silica yield value is $5.3 \%$, obtained by the treatment of $7.5 \% \mathrm{KOH}$ concentration with a heating duration of 10 minutes, while the lowest silica yield value is $1.48 \%$, obtained by the treatment of $2.5 \% \mathrm{KOH}$ concentration with a heating duration of 5 minutes.

Table 1 - Anova for Rice Husk Silica Extraction Yield

\begin{tabular}{c|cccccc}
\hline Source of Variation & SS & df & MS & F & P-value & F crit \\
\hline KOH concentration & 49.65816 & 2 & 24.82908 & 57.00942 & $1.63 \mathrm{E}-08$ & 3.554557 \\
Heating time & 1.309919 & 2 & 0.654959 & 1.503835 & 0.248915 & 3.554557 \\
Interaction & 0.092593 & 4 & 0.023148 & 0.05315 & 0.994238 & 2.927744 \\
Within / Error & 7.839467 & 18 & 0.435526 & & & \\
Total & 58.90014 & 26 & & & & \\
\hline
\end{tabular}

${ }^{\star} F=F$ value, $F$ crit $=F$ Table.

Based on the analysis of variance (ANOVA), it is shown that the $\mathrm{KOH}$ concentration factor had a significant effect on the results $(P>0.05)$, while the heating duration factor did not have a significant effect on the extraction value of silica $(P>0.05)$. According to Prasetio (2014), the higher the concentration of $\mathrm{KOH}$ added the more yields produced. The extraction duration also gives an effect on the yield produced. Short extraction duration will generate a 
low yield because not all components are extracted properly. With longer heating time, the contact time between the husk and $\mathrm{KOH}$ solution will be greater, therefore resulting greater yield (Irawan, 2010).

Physical characteristics of rice husk tablets were observed by SEM (Scanning Electron Microscopy) testing and it can be seen in Figure 3.

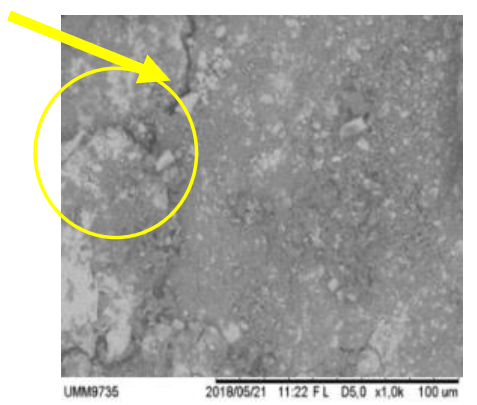

Figure 3 - Characteristics of Composition of Organic Material Rice Husk Tablets Using Scanning Electron Microscopy

Samples with $2.5 \% \mathrm{KOH}$ concentration and 5 minutes warm-up duration, where the surface was too tenuous. Samples with $5 \% \mathrm{KOH}$ concentration and 7.5 minutes warm-up duration had sufficient density but were not as comparable when compared to samples with $7.5 \%$ of $\mathrm{KOH}$ concentration and 10 minutes for warm-up time. Based on Figure 3, it can be seen in the yellow arrow that the structure of the tablet will be more tightly closed if the heating goes longer; moreover, the high concentration of $\mathrm{KOH}$ solution will cause the bond formed to be stronger and possess a high density. In Figure 3, there is also three visible parts in the yellow circle. The brightest part is inorganic material, for parts that are grey are organic materials and for the darkest colored parts are materials with a slow density, therefore they cannot be penetrated by waves.

From the data obtained by the sample with the best results, namely the treatment of $\mathrm{KOH}$ concentration as much as $7.5 \%$ with a heating duration of 10 minutes, then the chemical analysis of the sample was carried out using $X$ - rays to find out the elements contained in the figure 4 .

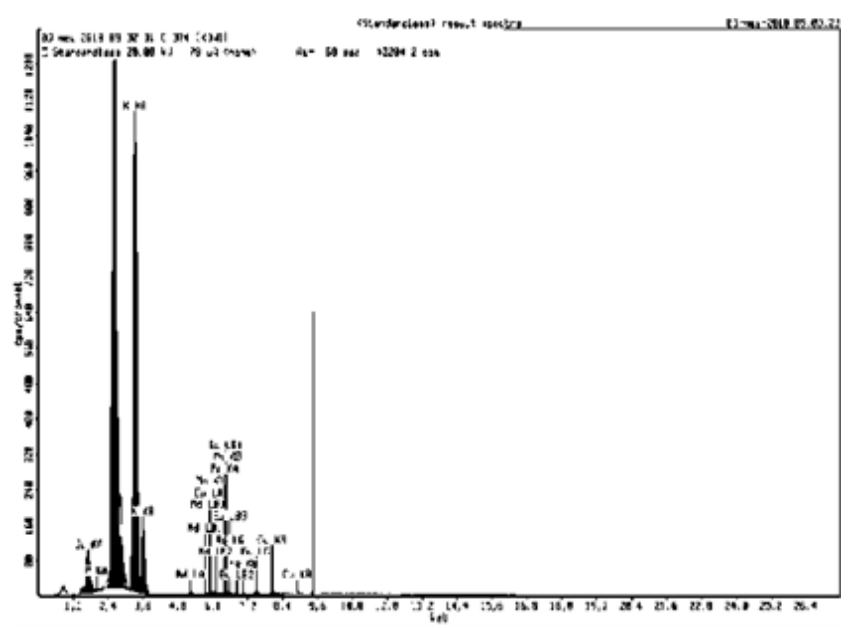

Figure 4-XRF Rice Husk Powder with the treatment of $7.5 \mathrm{KOH}$

Based on Figure 4, it can be seen that the most dominant element is Potassium. The second most elements is chlorine and the third most element is silica. Silica is the most elements contained in rice husk, but in this study the silica obtained was only 6.22. It was possibly due to the heating duration, the $\mathrm{KOH}$ solvent was saturated. Therefore, at the time of operation the solubility of the $\mathrm{KOH}$ solvent to silica was reduced. According to Laksmono 
(2002), the saturation of solvents is caused by the solubility of the solute decreases with increasing time; this is indicated by the decrease in solutes taken by the solvent. In addition, the length of operation allows the silica formed to degenerate and be settled in rice husk, thus silica in the filtrate decreases.

Table 2 - Duration of Solubility in Water

\begin{tabular}{c|cccc}
\hline Treatment & $\begin{array}{c}\mathrm{t}_{1}=5 \text { minutes } \\
\text { (minutes) }\end{array}$ & $\begin{array}{c}\mathrm{t}_{2}=7,5 \text { minutes } \\
\text { (minutes) }\end{array}$ & $\begin{array}{c}\mathrm{t}_{3}=10 \text { minutes } \\
\text { (minutes) }\end{array}$ & Time in soil soluble (minutes) \\
\hline $\mathrm{KOH} \mathrm{2,5 \%}$ & 40 & 40 & 45 & 40 \\
$\mathrm{KOH} \mathrm{5 \%}$ & 100 & 105 & 110 & 100 \\
$\mathrm{KOH} \mathrm{7,5 \%}$ & 150 & 150 & 155 & 150 \\
\hline
\end{tabular}

Table 3 - Water Testing Results with Percolation Method (500 ml of water, 1 gram of rice husk tablets)

\begin{tabular}{ccc}
\hline Parameter & Unit & Result \\
\hline Calium & $\mathrm{Mg} / \mathrm{L}$ & 74.89 \\
Clorin & $\mathrm{Mg} / \mathrm{L}$ & 0.11 \\
Silica & $\mathrm{Mg} / \mathrm{L}$ & 16.68 \\
\hline
\end{tabular}

Based on Table 2, the concentration of $2.5 \% \mathrm{KOH}$ with a warm up duration of 5 and 7.5 minutes has faster solubility, i.e. for 40 minutes, while $7.5 \% \mathrm{KOH}$ concentration with a warm up duration of 10 minutes had solubility in longer absorption for 155 minutes. The pores formed on the tablet will affect the solubility of the tablet in water (release). Spacing pores made it easier for water to enter the pores, therefore the tablet's release time can be faster. Meanwhile, the tight pores caused the water difficulty to enter the pores; therefore the tablet's release time became slower. Based on Table 2, the results of solubility in the soil were obtained. The sample with $2.5 \%$ solubility dissolved in the soil for 14 days, while the solubility of $5 \%$ can dissolve in the soil for 25 days, and for the solubility of $7.5 \%$ can dissolve in the soil for 37 days. Based on Table 3, results were obtained on percolation testing of water included in rice husk tablets. Potassium obtained in $500 \mathrm{ml}$ of water was $74.89 \mathrm{mg} / \mathrm{L}$, for chlorine obtained as much as $0.11 \mathrm{mg} / \mathrm{L}$, and the resulting silica was $16.68 \mathrm{mg} / \mathrm{L}$.

\section{CONCLUSION}

The results show that the extraction of silica from rice husks is found to range between $1.48-5.3 \%$. The results of the XRF analysis show that the largest silica value is $6.51 \%$. Based on these results, heating using microwave does not produce optimal silica results. The relationship between the concentration of $\mathrm{KOH}$ and hardness has a direct proportional result, while the length of heating duration with hardness is inversely proportional. The smallest results are obtained with a value of $1,131 \mathrm{Kgf}$ and the largest as much as 3,356 Kgf.

\section{REFERENCES}

1. Apricio, V., Costa, J.L., Zamora, M. 2008. Nitrate Leaching Assessment in a Long-term Experiment under Supplemantary Irrigation in Humid Argentina. Agricultural Water Management Vol.95, pp.1361-1372.

2. Handayani, P.A, Eko N, Wara D.P.R. 2015. Utilization of Rice Husk Waste to Silica Gel. Jurnal Bahan Alam Terbarukan. Vol 4 (2): 55-59. DOI 10.15294/jbat.v3i2.3698.

3. Indriani, D.W, Nunun B, Sumardi H and Habib E. 2018. Optimation of Silica Extraction of Rice Husk (Oryza Sativa L) to Increase Adsorption Plant Nutrients. Journal of Environmental Engineering and Sustainable Technology. Vol 5(2): $71-75$.

4. Irawan, B. 2010. Patchouli Oil Quality Improvement by Extraction and Distillation in Various Solvent Compositions. Faculty of Chemical Engineering Diponegoro University: Semarang.

5. Ismunadji, M and W. Dijkshoorn. 1971. Nitrogen Nutrition of Rice Plants Measured by Growth and Nutrient Content in Pot Experiments. Ionic Balance and Selective Uptake. Neth. J. Agric. Sci., 19: 223-236. 
6. Laksmono, J.A. 2002. Utilization of Rice Husk Ash as a Raw Material for Silica. Seminar on the Challenges of Chemical Research in the Era of Globalization and the Era of Super Information. Indonesian Institute of Sciences. Jakarta, 17 September 2002.

7. Novari, F., Sukanton, E., Sitorus, S. 2007. Isolation and Determination of Essential Oil Levels From Leaves and Cinnamon Bark (Cinnamomum Burmannii BI.) Using the Gas Chromatography Method. Jurnal Kehutanan Unmul 3 (1).

8. Soekarto. 1990. The Basics of Food Quality Supervision and Standardization. Book. Bogor Agricultural Institute: Bogor.

9. Soeswanto, B and Ninik L. 2011. Utilization of Rice Ash Waste Sodium Silicate. Jurnal Fluida. Vol 7 (1): 18 -22.

10. Sumarmono. 2012. Measurement of Meat Tenderness with a Penetrometer. Animal Product Technology Laboratory, Faculty of Animal Husbandry. Jendral Soedirman University. Purwokerto. 